\title{
Clinical Outcomes of Dose-escalated Radiotherapy for Localised Prostate Cancer: A Single-institution Experience
}

\author{
KATHERINE MENG, KEITH LIM, CHIA CHING LEE, DAVID CHIA, \\ KIAT HUAT OOI, YU YANG SOON and JEREMY TEY
}

Department of Radiation Oncology, National University Cancer Institute, Singapore, Singapore

\begin{abstract}
Background/Aim: To report the outcomes of patients with prostate cancer treated with dose-escalated radiotherapy over a 15-year period at our Institution. Patients and Methods: Patients with biopsy-proven cT1-4NOMO disease who received radical external beam radiotherapy (EBRT) were reviewed. The endpoints were 5-year overall survival (OS), freedom from biochemical failure $(F F B F)$ and late treatment toxicities. Results: A total of 236 patients were eligible. Median follow-up was 70 months. Low-, intermediate- and high-risk disease was found in 9\%; 29\% and 62\% of patients, respectively. The median radiation dose was $73.8 \mathrm{~Gy}$. Overall $42 \%$ of patients had dose escalation to $>74$ Gy. Five-year OS and FFBF were $95.2 \% / 81.6 \% / 75.4 \%$ and $95.0 \% / 98.0 \% / 82.0 \%$ for low/intermediate-/high-risk patients, respectively. Dose escalation to $>74$ Gy did not improve FFBF (hazard ratio $=0.97,95 \%$ confidence intervaI $=0.43-2.19, p=0.93)$ and was associated with a 4.3-fold increase in the odds of grade 3 or more rectal bleeding ( $p<0.01)$. Conclusion: Dose escalation to $>74 \mathrm{~Gy}$ did not improve OS or FFBF but was associated with a higher rate of grade 3 or more rectal haemorrhage.
\end{abstract}

Prostate cancer is one of the most common types of cancer among men in Singapore, accounting for one in every seven cancer diagnoses (1). Following a rising incidence in recent years, more than 4,000 new cases were diagnosed between 2011-2015, in part due to an ageing population as well as enhanced awareness and opportunistic screening (2-4).

This article is freely accessible online.

Correspondence to: Dr. Jeremy Tey, Radiation Oncologist, Department of Radiation Oncology, National University Hospital, National University Cancer Institute, NUHS Tower Block Level 7, 1E Kent Ridge Road, Singapore 119228, Singapore. E-mail: jeremy_tey@nuhs.edu.sg

Key Words: Prostate cancer, radiotherapy, toxicity, proctitis, dose escalation, androgen deprivation therapy.
External beam radiotherapy (EBRT) is one of the curative treatments for clinically localised prostate cancer, with disease-specific survival comparable to that for radical prostatectomy $(5,6)$. Long-term toxicities following RT, particularly relating to bowel function, remain problematic (7). The advent of intensity-modulated radiotherapy (IMRT) as the standard of care for delivery of prostate EBRT has resulted in improved biochemical control through dose escalation whilst reducing treatment-related toxicity (8-10). However, to date there are limited reports detailing the treatment of prostate cancer utilising modern RT techniques in an Asian population, despite the trend of increased disease burden. This study aimed to review both the clinical and toxicity outcomes of RT dose escalation in a patient cohort treated at a tertiary centre in Singapore.

\section{Patients and Methods}

Patients. Approval for this study was obtained from the Institutional Review Board (NHG 2017/00934). Patients with biopsy-proven prostate cancer who received curative-intent EBRT with or without androgen deprivation therapy (ADT) at our Institution between January 2002 and December 2015 were retrospectively reviewed. Pelvic computed tomography/magnetic resonance imaging, and bone scan were used for staging. Patients with clinical/radiological nodal or distant metastases were excluded. Patients who received prostate brachytherapy were excluded. D'Amico classification was used to categorise eligible patients into low-, intermediate- and high-risk groups based on initial prostate-specific antigen (PSA) level, tumour stage (American Joint Cancer Committee seventh edition) and Gleason score (11).

Radiotherapy. All patients received EBRT in 1.8-2.0 Gy daily fractions, 5 days a week, with bladder and bowel preparation according to Department protocol. Treatment was delivered via 3dimensional conformal (3D-CRT) technique or IMRT from 2006 onwards. The planning target volume (PTV) for patients treated with IMRT consisted of the clinical target volume (CTV) with a 1$\mathrm{cm}$ circumference except for posterior prostate-rectum interface where a $0.5 \mathrm{~cm}$ margin was adopted. Prior to 2009 , patients with low-, intermediate- and high-risk prostate cancer were treated to a standardised dose of 73.8 Gy in 41 fractions. After 2009, the dose 
prescriptions and target volumes were as follows. Low-risk patients were treated to $78 \mathrm{~Gy}$ in a single phase with CTV including the whole prostate. Intermediate- and high-risk patients were treated in two phases to a total of 79.2 Gy: Phase one CTV encompassed the whole prostate and bilateral seminal vesicles to 54 Gy in 27 fractions, phase two boosted the prostate and proximal seminal vesicles by an additional $25.2 \mathrm{~Gy}$ in 14 fractions. Additional whole pelvis irradiation was given to patients with $>15 \%$ risk of pelvic lymph node involvement according to the Roach formula (12). Where prescribed, 48.6 Gy in 27 fractions was delivered to the pelvic lymph nodes during phase one with a simultaneous integrated boost technique.

$A D T$. In addition to EBRT, intermediate- and high-risk patients received $\mathrm{ADT}$ in the form of luteinizing hormone-releasing hormone agonist as a subcutaneous injection for 4-6 months and 2-3 years respectively. At least 2 months of neoadjuvant ADT is given prior to initiation of RT.

Data collection. Clinical data were obtained through institutional electronic medical records and RT databases. Information recorded included details pertaining to patient demographics (age, ethnicity, performance status), disease characteristics (histology, Gleason score, PSA level, clinical T stage), RT parameters (technique, total dose, dose-fractionation, whole pelvis irradiation), ADT (type, timing and duration), long-term complications (incidence of rectal bleeding/haematuria, cardiotoxicity in patients who received ADT as indicated by acute myocardial infarction (AMI) or abnormal echocardiograms, as well as treatment outcomes (biochemical recurrence, pattern of locoregional/distant metastasis, cause of death). Follow-up data based on patients' clinical records were collected until their time of death or the most recent review up to August 2018

Follow-up. Patients were followed up post RT completion as per department protocol at 6 weeks, 3-monthly until the end of year 2, 6-monthly until the end of year 5 and annually thereafter until end of year 10. PSA testing was performed at every follow-up visit. Restaging work-up was carried out if clinically indicated.

Clinical outcomes. The primary endpoint was 5-year overall survival (OS), defined as the time from first treatment to death due to any cause or the last follow-up. The secondary endpoint was 5year freedom from biochemical failure (FFBF) as per Phoenix definition, i.e. a documented PSA rise by $2 \mathrm{ng} / \mathrm{ml}$ or more above the nadir level (13).

Toxicity outcomes. Treatment toxicities were graded based on Common Terminology Criteria for Adverse Events (CTCAE) version (v) 4.03 (14). We focused on rates of rectal haemorrhage, haematuria as well as incidence of urethral stricture post RT. Grade 2 rectal haemorrhage was defined as rectal bleeding requiring medical intervention (e.g. steroid enemas) with/without a single elective endoscopic evaluation with argon plasma coagulation/no intervention. Patients who underwent two or more sessions of argon plasma coagulation, rectal formalin application, hyperbaric oxygen therapy with/without blood transfusion(s) as a result of rectal bleeding were coded as experiencing grade 3 adverse events. For radiation cystitis, patients who developed gross haematuria necessitating elective endoscopic intervention (e.g. cystodiathermy),
Table I. Patient characteristics at baseline $(N=236)$.

\begin{tabular}{|c|c|}
\hline Characteristic & Value \\
\hline \multicolumn{2}{|l|}{ Follow-up duration, months } \\
\hline Median (range) & $70.1(1.43-169)$ \\
\hline \multicolumn{2}{|l|}{ Age at diagnosis, years } \\
\hline Median (range) & $72(48-89)$ \\
\hline \multicolumn{2}{|c|}{ ECOG performance status, n (\%) } \\
\hline 0 & $28(11.9)$ \\
\hline 1 & $193(81.8)$ \\
\hline 2 & $15(6.3)$ \\
\hline \multicolumn{2}{|l|}{ Smoking habit, n (\%) } \\
\hline Current smoker & $11(4.7)$ \\
\hline Never smoker & $45(19.1)$ \\
\hline Ex-smoker & $48(20.3)$ \\
\hline Unknown & $132(55.9)$ \\
\hline \multicolumn{2}{|c|}{ Pre-existing ischaemic heart disease, $\mathrm{n}(\%)$} \\
\hline Yes & $50(21.2)$ \\
\hline No & $186(78.8)$ \\
\hline \multicolumn{2}{|l|}{ Use of aspirin, $\mathrm{n}(\%)$} \\
\hline Yes & $62(26.3)$ \\
\hline No & $174(73.7)$ \\
\hline \multicolumn{2}{|l|}{ Staging: } \\
\hline \multicolumn{2}{|l|}{ MRI pelvis/prostate, $\mathrm{n}(\%)$} \\
\hline Yes & $75(31.8)$ \\
\hline No & $161(68.2)$ \\
\hline \multicolumn{2}{|c|}{$\mathrm{CT}$ abdomen/pelvis, $\mathrm{n}(\%)$} \\
\hline Yes & $151(64.0)$ \\
\hline No & $85(36.0)$ \\
\hline \multicolumn{2}{|l|}{ Bone scan, n (\%) } \\
\hline Yes & $212(89.8)$ \\
\hline No & $24(10.2)$ \\
\hline \multicolumn{2}{|l|}{ Histology, n (\%) } \\
\hline Acinar adenocarcinoma & $232(98.3)$ \\
\hline Other & $2(0.8)$ \\
\hline Unknown & $2(0.8)$ \\
\hline \multicolumn{2}{|l|}{ T-Stage, n (\%) } \\
\hline 1 & 114 \\
\hline 2 & 76 \\
\hline $3 a / 3 b$ & $21 / 12$ \\
\hline 4 & 12 \\
\hline Unknown & 2 \\
\hline \multicolumn{2}{|l|}{ Gleason grade group, $\mathrm{n}(\%)$} \\
\hline 1 & $62(26.6)$ \\
\hline 2 & $52(22.3)$ \\
\hline 3 & $36(15.5)$ \\
\hline 4 & $39(16.7)$ \\
\hline 5 & $44(18.9)$ \\
\hline Unknown & $3(1.3)$ \\
\hline \multicolumn{2}{|l|}{ Pre-treatment PSA, ng/ml } \\
\hline Median (range) & $17.3(0.87-530.4)$ \\
\hline \multicolumn{2}{|c|}{ D'Amico risk category, $\mathrm{n}(\%)^{*}$} \\
\hline Low-risk & $21(8.9)$ \\
\hline Intermediate-risk & $69(29.2)$ \\
\hline High-risk & $146(61.9)$ \\
\hline
\end{tabular}

CT: Computed tomography; ECOG: Eastern Cooperative Oncology Group; MRI: magnetic resonance imaging; PSA: prostate specific antigen; *D'Amico risk categories: Low-risk: Gleason score $<6$, PSA $<10 \mathrm{ng} / \mathrm{ml}$ and clinical stage T1c or T2a; intermediate-risk: Gleason score 7 or PSA $10-20 \mathrm{ng} / \mathrm{ml}$ or clinical stage T2b; high risk: Gleason score $8-10$ or PSA $>20 \mathrm{ng} / \mathrm{ml}$ or clinical stage T2c, T3, T4. 
Table II. Treatment characteristics $(N=236)$.

\begin{tabular}{lc}
\hline Characteristic & Value \\
\hline Prescribed radiation dose, Gy* & \\
$\quad$ Median (range) & $73.8(70.2-82.2)$ \\
Radiation technique, n (\%) & $32(13.6)$ \\
3D-CRT & $204(86.4)$ \\
IMRT or Arc therapy & $137(58.0)$ \\
Dose escalation to $\geq 74$ Gy, n (\%) & $99(42.0)$ \\
Yes & \\
No & $173(73.3)$ \\
Whole pelvis radiation therapy, n (\%) & $59(25.0)$ \\
Yes & $4(1.7)$ \\
No & \\
Unknown & $206(87.3)$ \\
Neoadjuvant; concurrent/adjuvant ADT, n (\%) & $30(12.7)$ \\
Yes & \\
No & $164(79.6)$ \\
ADT duration $\geq 6$ months (N=206), n (\%) & $42(20.4)$ \\
Yes &
\end{tabular}

3D-CRT: 3-Dimensional conformal radiation therapy; IMRT: intensitymodulated radiation therapy; ADT: androgen-deprivation therapy. *Equivalent dose in 2 Gy fractions.

blood transfusion or hospitalisation were coded as experiencing grade 3 adverse events. Required treatment (if any) for urethral strictures diagnosed post RT was documented.

Statistical analysis. Univariable and multivariable Cox proportional hazard regression models were performed to identify independent factors with significant impacts on patient survival. OS was calculated using the Kaplan-Meier method. The statistical level of significance for all tests was set at 0.05 . Analyses were performed using STATA version 14 (Stata Corp., College Station, TX, USA).

\section{Results}

Patient characteristics. A total of 236 eligible patients were identified, with a median follow-up period of 70.1 months (range $=1.43-169$ ) as shown in Table I. The median age at diagnosis was 72 (range $=48-89$ ) years. The majority of patients had an Eastern Cooperative Oncology Group performance status (ECOG PS) of 0 or 1 (93.6\%). According to D'Amico risk classification, $21(8.9 \%), 69(29.2 \%)$ and $146(61.9 \%)$ patients had low-, intermediate- and high-risk disease respectively.

$R T$ and $A D T$. Treatment characteristics are outlined in Table II. The median prescribed radiation dose was $73.8 \mathrm{~Gy}$ (range=70.2-82.2 Gy). IMRT technique was used in 204 $(86.4 \%)$ patients, while 3D-CRT was used to treat the in the remaining 32 patients $(13.6 \%)$. The full prescribed course of RT was completed in $233(98.7 \%)$ patients. Dose escalation
Table III. Clinical outcomes.

\begin{tabular}{lrrrrrrrr}
\hline & \multicolumn{3}{c}{ OS (\%) } & & \multicolumn{3}{c}{ FFBF (\%) } \\
\cline { 2 - 3 } \cline { 7 - 8 } D'Amico risk group & 1-Year & 3-Year & 5-Year & & 1-Year & 3-Year & 5-Year \\
\hline All & 97.5 & 88.5 & 79.2 & & & \\
Low-risk & 100.0 & 95.2 & 95.2 & & 100.0 & 95.2 & 95.0 \\
Intermediate-risk & 97.1 & 89.5 & 81.6 & & 100.0 & 100.0 & 98.0 \\
High-risk & 97.3 & 87.1 & 75.4 & & 96.5 & 92.0 & 82.0 \\
\hline
\end{tabular}

OS: Overall survival; FFBF: freedom from biochemical failure (Phoenix criteria).

to 74 Gy or more was achieved in $99(42.0 \%)$ patients. Whole pelvis radiation was given in $173(73.3 \%)$ patients.

ADT was given to $206(87.3 \%)$ patients mainly in the form of 1- and 3-monthly subcutaneous leuprolide at a dose of $3.75 \mathrm{mg}$ and $11.25 \mathrm{mg}$ or subcutaneous goserelin at a dose of $3.6 \mathrm{mg}$ and $10.8 \mathrm{mg}$ lasting for the planned duration of hormone therapy. Of the patients who received ADT, 164 $(79.6 \%)$ had more than 6 months of treatment.

Patterns of recurrence. Overall, 24 (10.2\%) patients developed biochemical recurrence during follow-up, most $(87.5 \%)$ of whom had high-risk disease. Distant metastases developed in $27(11.4 \%)$ patients in the same time period. Of these, $19(70.4 \%)$ had disease to bone, $5(26.3 \%)$ to lung, 8 $(33.9 \%)$ to lymph nodes below diaphragm, 3 (10.3\%) to lymph nodes above diaphragm, and $1(3.4 \%)$ to the liver. There were no local recurrences detected in the prostate.

Cause of death. At the end of the follow-up period, 45 (19.1\%) patients had died, of whom four $(8.9 \%)$ as a consequence of metastatic prostate cancer, all of whom had high-risk disease. Seven deaths $(15.6 \%)$ were attributed to cardiac causes including AMI, all had been treated with ADT (mean duration=2.6 years) and five had pre-existing ischaemic heart disease.

Clinical and toxicity outcomes. The overall 5-year OS for all patients was $79.2 \%$. For low-, intermediate- and high-risk patient groups, the 5-year OS was $95.2 \%, 81.6 \%$ and $75.4 \%$, and the 5-year FFBF was $95.0 \%, 98.0 \%$ and $82.0 \%$ respectively (Table III). The Kaplan-Meier survival estimates for FFBF and OS by risk categories are shown in Figures 1 and 2 .

Univariable analysis showed that Gleason grade group 4 and 5 [hazard ratio $(\mathrm{HR})=2.22,95 \%$ confidence interval $(\mathrm{CI})=1.05-4.66, p=0.036$; and $\mathrm{HR}=2.34,95 \% \mathrm{CI}=1.16-4.74$, $p=0.018$, D'Amico high-risk category ( $\mathrm{HR}=5.69,95 \%$ $\mathrm{CI}=1.38-23.40, p=0.016)$ and ECOG PS 2 (HR=17.86, 95\% $\mathrm{CI}=4.96-64.24, p=0.001)$ were significantly associated with 


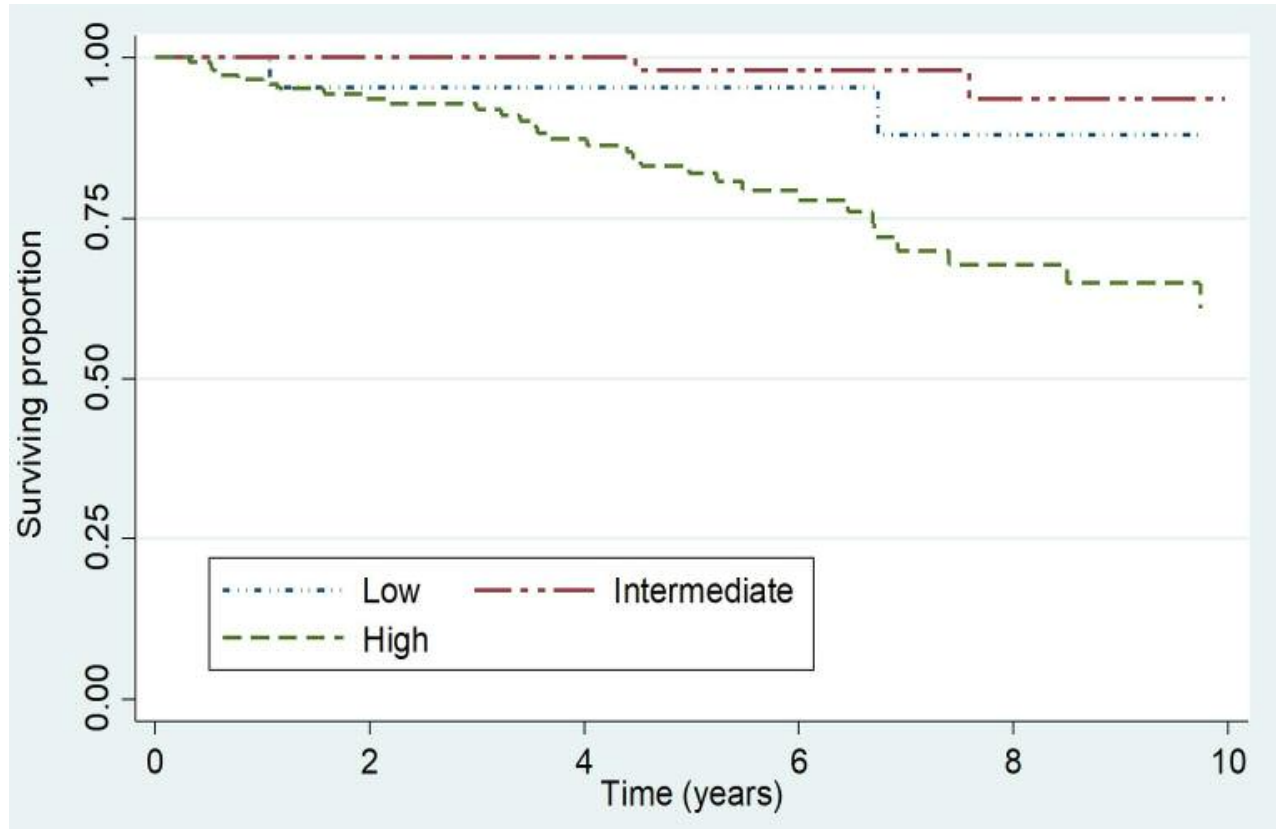

Figure 1. Freedom from biochemical failure by prostate cancer risk category according to Kaplan-Meier survival estimates.

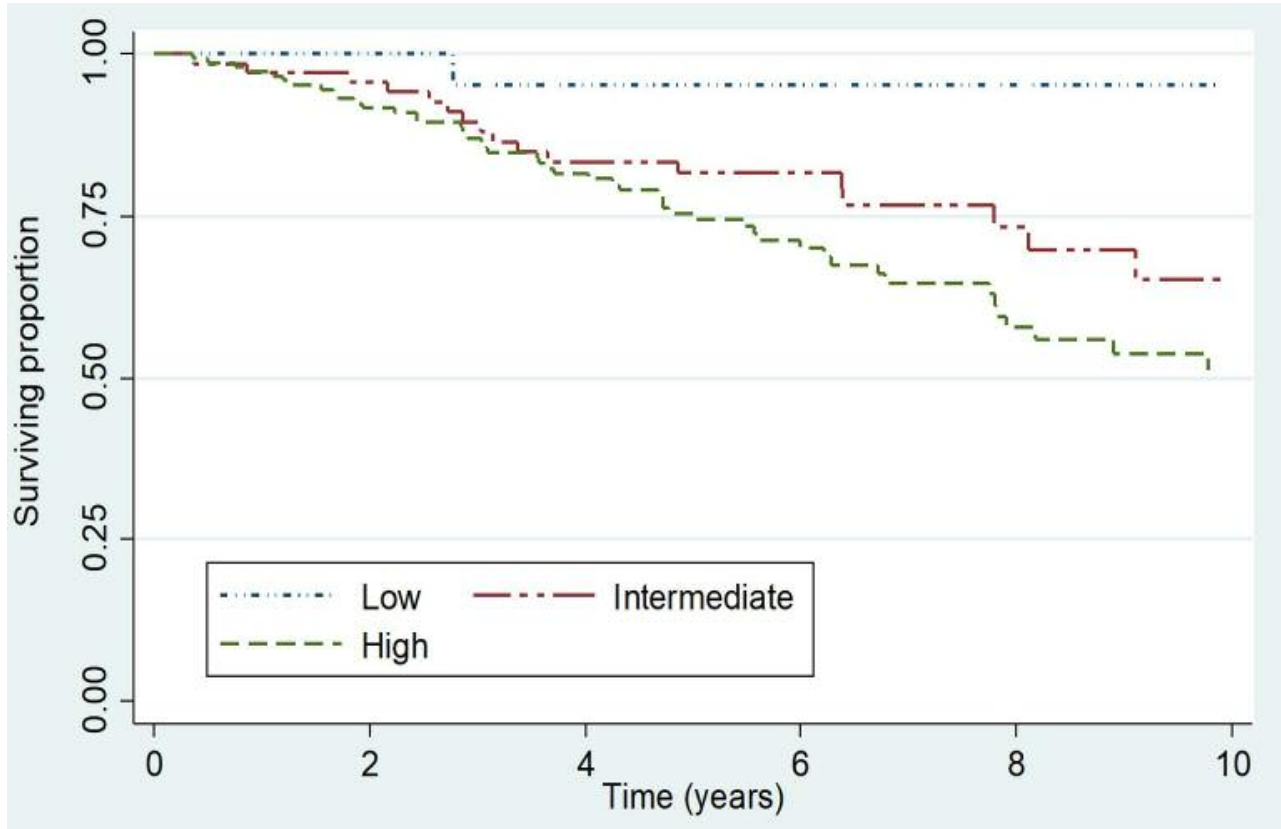

Figure 2. Overall survival by prostate cancer risk category according to Kaplan-Meier survival estimates.

an increased hazard of death. RT technique (IMRT vs. 3DCRT) and dose escalation to $\geq 74$ Gy were not significantly associated with OS on both univariable and multivariable analyses (Table IV).
On the other hand, only Gleason grade group 3 and 5 $(\mathrm{HR}=3.80,95 \% \mathrm{CI}=1.40-10.31, p=0.009$, and $\mathrm{HR}=3.75$, 95\% CI=1.47-9.58, $p=0.006)$ were significantly associated with an increased risk of biochemical failure (Table V). Dose 
Table IV. Univariable and multivariable Cox proportion hazard regression on all-cause death.

\begin{tabular}{|c|c|c|c|c|c|c|c|}
\hline \multirow[b]{2}{*}{ Characteristic } & & \multicolumn{3}{|c|}{ Univariable } & \multicolumn{3}{|c|}{ Multivariable* } \\
\hline & & HR & $95 \% \mathrm{CI}$ & $p$-Value & HR & $95 \% \mathrm{CI}$ & $p$-Value \\
\hline Age at diagnosis & Per year & 1.07 & $1.03-1.11$ & $<0.01$ & 1.05 & $0.95-1.15$ & 0.32 \\
\hline \multirow[t]{3}{*}{ ECOG performance status } & 0 & Ref & & & & & \\
\hline & 1 & 4.15 & $1.29-13.28$ & 0.02 & 1.35 & $0.32-5.66$ & 0.68 \\
\hline & 2 & 17.86 & $4.96-64.24$ & $<0.01$ & 3.00 & $0.41-22.14$ & 0.28 \\
\hline Staging using MRI pelvis/prostate & Yes $v s$. no & 1.07 & $0.62-1.85$ & 0.801 & & & \\
\hline \multirow[t]{5}{*}{ Gleason grade group } & 1 & Ref & & & & & \\
\hline & 2 & 1.49 & $0.72-3.06$ & 0.28 & 0.95 & $0.31-2.93$ & 0.94 \\
\hline & 3 & 1.78 & $0.80-3.95$ & 0.16 & 0.22 & $0.02-2.03$ & 0.18 \\
\hline & 4 & 2.22 & $1.05-4.66$ & 0.04 & 0.88 & $0.23-3.30$ & 0.85 \\
\hline & 5 & 2.34 & $1.16-4.74$ & 0.02 & 0.78 & $0.20-2.99$ & 0.72 \\
\hline \multirow[t]{3}{*}{ D'Amico risk category } & Low & Ref & & & & & \\
\hline & Intermediate & 3.71 & $0.86-16.00$ & 0.08 & 2.95 & $0.32-26.93$ & 0.34 \\
\hline & High & 5.69 & $1.38-23.40$ & 0.02 & 5.88 & $0.67-52.03$ & 0.11 \\
\hline \multirow[t]{2}{*}{ RT delivery } & 3D-CRT & Ref & & & & & \\
\hline & IMRT or Arc therapy & 1.23 & $0.65-2.32$ & 0.53 & & & \\
\hline \multirow[t]{2}{*}{ Dose escalation } & $<74 \mathrm{~Gy}$ & Ref & & & & & \\
\hline & $\geq 74 \mathrm{~Gy}$ & 1.29 & $0.74-2.28$ & 0.37 & & & \\
\hline
\end{tabular}

3D-CRT: 3-Dimensional conformal radiation therapy; ECOG: Eastern Cooperative Oncology Group; IMRT: intensity-modulated radiation therapy; MRI: magnetic resonance imaging; RT: radiotherapy. *Included covariates with $p<0.10$ on univariable analysis.

escalation to $\geq 74$ Gy did not significantly improve FFBF $(\mathrm{HR}=0.97,95 \% \mathrm{CI}=0.43-2.19, p=0.93)$.

The cumulative incidence of grade 3 rectal bleeding and haematuria were $9.3 \%$ and $1.7 \%$, respectively. There were no grade 4 or 5 toxicities reported (Table VI). The median onset of grade 3 rectal bleeding from start of EBRT was 14.7 months (range=6.2-58.7 months). Logistic regression showed that dose escalation to $\geq 74$ Gy increased the odds of developing grade 3 or more proctitis by 4.3 times $(p=0.004)$. No positive correlation was demonstrated between RT technique (IMRT $v s$. 3D-CRT), whole pelvis RT or the use of aspirin (Table VII). Urethral stricture developed in $14(5.9 \%)$ patients, of which nine $(64.3 \%)$ required intervention such as dilatation and optical urethrotomy.

AMI developed in $28(11.9 \%)$ patients during follow-up, eight $(28.6 \%)$ of whom had documented pre-exiting ischaemic heart disease (IHD). ADT was given to 26 (92.9\%) patients for an average of 1.8 years. The mean interval of onset of AMI after first RT fraction was 4.0 years. The use of ADT did not appear to be significantly associated with increased odds of developing AMI during or after treatment [odds ratio $(\mathrm{OR})=4.40,95 \% \mathrm{CI}=0.58-33.63, p=0.153]$.

\section{Discussion}

In our study of 236 patients with node-negative nonmetastatic prostate cancer who underwent definitive EBRT with or without ADT, 5-year OS was 95.2\%, 81.6\% and
$75.4 \%$; and FFBF was $95.0 \%, 98.0 \%$ and $82.0 \%$ for low-, intermediate- and high-risk patients, respectively. This is comparable with internationally published data $(5,15,16)$. To our knowledge this is the largest series reporting prostate cancer outcomes after RT in South-East Asia.

This cohort comprised a sizable number of D'Amico highrisk patients $(61.9 \%)$ and the majority were treated with IMRT (86.4\%). Although dose escalation to between 74-80 Gy has been shown to improve FFBF in multiple previous trials (17-20), particularly in patients with intermediate- to high-risk disease $(9,21,22)$, our results suggest that there was no significant reduction in biochemical recurrence or survival benefit seen at 5 years. The reason for this apparent difference may be two-fold. Firstly, our study included a significant proportion of patients treated with ADT. Longterm results from several large randomised trials have demonstrated that ADT reduced biochemical failure and improved OS in patients with intermediate to high-risk disease (23-26). However, ADT use was typically excluded in the aforementioned dose-escalation trials $(17,18,21,22)$, accounted for only a small proportion of the cohort (19), or was limited to a short duration (neoadjuvant and concurrent) (20). In our study, $87.3 \%$ of the patients received ADT and $79.6 \%$ were treated for more than 6 months in duration. This may have contributed to overall better biochemical and survival outcomes, neutralising the potential benefit of dose escalation. Secondly, the median follow-up of 70 months (5.8 years) in our study was relatively shorter than the 
Table V. Univariable Cox proportion hazard regression on biochemical failure.

\begin{tabular}{|c|c|c|c|}
\hline \multirow[b]{2}{*}{ Characteristic } & \multicolumn{3}{|c|}{ Univariable } \\
\hline & HR & $95 \% \mathrm{CI}$ & $p$-Value \\
\hline \multicolumn{4}{|l|}{ Age at diagnosis } \\
\hline Per year & 0.95 & $0.90-0.99$ & 0.02 \\
\hline \multicolumn{4}{|l|}{ ECOG performance status } \\
\hline 0 & Ref & & \\
\hline 1 & 1.14 & $0.44-2.96$ & 0.79 \\
\hline 2 & 0.66 & $0.08-5.71$ & 0.71 \\
\hline \multicolumn{4}{|c|}{ Staging using MRI pelvis/prostate } \\
\hline Yes vs. no & 0.47 & $0.18-1.22$ & 0.12 \\
\hline \multicolumn{4}{|l|}{ Gleason grade group } \\
\hline 1 & Ref & & \\
\hline 2 & 0.73 & $0.19-2.82$ & 0.645 \\
\hline 3 & 3.80 & $1.40-10.31$ & 0.01 \\
\hline 4 & 1.06 & $0.27-4.13$ & 0.93 \\
\hline 5 & 3.75 & $1.47-9.58$ & 0.01 \\
\hline \multicolumn{4}{|l|}{ D'Amico risk category } \\
\hline Low & Ref & & \\
\hline Intermediate & 0.39 & $0.05-2.76$ & 0.35 \\
\hline High & 3.63 & $0.86-15.23$ & 0.08 \\
\hline \multicolumn{4}{|l|}{ RT delivery } \\
\hline 3D-CRT & Ref & & \\
\hline IMRT or Arc therapy & 1.12 & $0.46-2.74$ & 0.80 \\
\hline \multicolumn{4}{|l|}{ Dose escalation } \\
\hline$<74$ Gy & Ref & & \\
\hline$\geq 74 \mathrm{~Gy}$ & 0.97 & $0.43-2.19$ & 0.93 \\
\hline
\end{tabular}

CI: Confidence intervaI; 3D-CRT: 3-dimensional conformal radiation therapy; ECOG: Eastern Cooperative Oncology Group; HR: hazard ratio; IMRT: intensity-modulated radiation therapy; MRI: magnetic resonance imaging; RT: radiotherapy.

average for dose-escalation trials which regularly followedup patients for more than 10 years, thereby accruing a larger number of events (biochemical recurrences and deaths) which may in turn translate into therapeutic benefit.

Controversy remains concerning the association between ADT use and cardiovascular complications. Mechanisms proposed include insulin resistance and impaired arterial vasculature function secondary to induced hypogonadism. Results from large observational studies suggest that men more than 65 years of age are especially susceptible (27-29). However, conflicting evidence from multiple randomised phase III trials showed that neoadjuvant, and adjuvant as well as total longer duration of ADT (up to 28 months) were not associated with increased cardiovascular mortality (3032 ). With regards to cardiac morbidity, in a large propensitymatched analysis of more than 19,000 ADT users and nonusers, Alibhai et al. found ADT not to be associated with increased AMI at 6.5 years of follow-up (33). Our results were in line with this. However, owing to the fact that the number of events in our study was fairly small (28 AMIs and
Table VI. Incidence of radiation induced rectal bleeding and haematuria.

\begin{tabular}{lcccc}
\hline \multicolumn{5}{c}{ Grade, n (\%) } \\
\hline CTCAE term & 2 & 3 & 4 & 5 \\
Rectal haemorrhage & $29(12.3)$ & $22(9.3)$ & 0 & 0 \\
Haematuria & $13(5.5)$ & $4(1.7)$ & 0 & 0 \\
\hline
\end{tabular}

CTCAE Common Terminology Criteria for Adverse Events v4.03 (14).

Table VII. Univariable logistic regression on grade 3 or more rectal bleeding.

\begin{tabular}{lccc}
\hline & \multicolumn{3}{c}{ Grade $\geq 3$ rectal bleeding } \\
\cline { 2 - 4 } Characteristic & OR & $95 \%$ CI & $p$-Value \\
\hline Dose escalation to $\geq 74$ Gy $(v s .<74$ Gy $)$ & 4.21 & $1.58-11.19$ & $<0.01$ \\
IMRT or Arc therapy $(v s .3 D-C R T)$ & 3.56 & $0.46-27.41$ & 0.22 \\
Whole pelvis radiation therapy & 1.18 & $0.41-3.34$ & 0.76 \\
Use of aspirin & 0.26 & $0.058-1.13$ & 0.07 \\
\hline
\end{tabular}

CI: Confidence intervaI; 3D-CRT: 3-dimensional conformal radiation therapy; IMRT: intensity-modulated radiation therapy; OR: odds ratio.

seven cardiovascular-related deaths), longer follow-up of a larger patient population is required for a more definitive conclusion.

Late rectal and bladder toxicity are common after prostate EBRT, frequently manifesting as haemorrhage secondary to formation of friable neovasculature and non-healing mucosal ulceration, on the background of fibrosis and chronic ischaemia $(34,35)$. Multiple patient (e.g. anticoagulation, comorbidities such as diabetes mellitus, inflammatory bowel disease) $(31,36)$, disease and radiation characteristics $(e . g$. total dose, dose per fraction, irradiated organ-at-risk volume, delivery modality) $(9,10,35,37)$ have been suggested to play a part. Unfortunately, there is considerable variation amongst studies looking at the incidence of chronic radiation proctitis/cystitis owing to the lack of consensus on its reporting and definition. Furthermore, significant heterogeneity in patient selection, dose/modality of radiotherapy, presence or absence of adjunct use such as rectal balloon, concomitant use of ADT and duration of follow-up limits the value of direct comparison.

This difficulty is emblematic of the accuracy and consistency of radiation toxicity results analysis across multiple studies through time. Zhen et al. investigated the utilisation patterns of three most commonly used standards for grading tissue toxicities induced by radiation (38). They found that the CTCAE system (39) has been gaining popularity over recent years and is particularly favoured in 
lung, breast and prostate studies, alongside the Radiation Therapy Oncology Group grading scale (40). In our study, the CTCAE grading system was chosen given that it is the most up-to-date, comprehensive and developed by drawing on the strengths of previous instruments. Focus was placed on the incidence of rectal bleeding and haematuria, which lends itself to further endoscopic investigation. The cause of symptoms, radiation-induced or otherwise, may be determined more objectively. This is in contrast with other symptoms such as urinary frequency or urgency which may be indicative of or compounded by background prostatic hyperplasia.

When managing patients presenting with radiation-induced rectal haemorrhage or haematuria, many clinicians may elect to withhold any antiplatelet or anticoagulation agents. Interestingly, the daily use of aspirin $(100 \mathrm{mg})$ approached significance as a protective factor for more than grade 3 rectal bleeding ( $\mathrm{OR}=0.26, p=0.072$ ) in our study. Aspirin is a commonly used drug in the prostate cancer population, and, through mechanisms not yet completely elucidated, has been associated with 5-year FFBF benefit in high-risk patients treated with both EBRT and radical prostatectomy, and OS benefit for the Gleason 9-10 subset $(41,42)$. Data are conflicting, however, regarding its potential role in exacerbating acute and late toxicities. Choe et al. reported that 79 patients who received warfarin or clopidogrel during prostate EBRT had significantly increased risk of developing more than grade 3 bleeding toxicity $(15.5 \%$ vs. $3.6 \%$, $p<0.0001$ ), and that use of IMRT modality in this group actually further enhanced the bleeding risk (31). On the other hand, Mikell et al. showed that in 210 patients on low-dose aspirin during EBRT, acute genitourinary toxicity was reduced ( $\mathrm{OR}=0.73, p=0.40)$ (43). In addition, there was a trend towards reduced late gastrointestinal toxicity $(\mathrm{OR}=0.69$, $p=0.056$ ), echoing the results of the current study. This suggests a possible unique anti-inflammatory effect of aspirin (over other antiplatelet/anticoagulation agents) which counteracts radiation-induced acute and late tissue injuries, which warrants further investigation.

The strengths of this study are: Firstly, target volume contouring was standardised in accordance to the Radiation Therapy Oncology Group contouring atlas (43). Secondly, all treatment plans were subjected to peer review within 1week of starting treatment as part of a rigorous quality assurance program. Limitations included: Firstly, the retrospective nature of the study, which might introduce reviewer bias, leading to under-reporting of treatment toxicities. Secondly, a relatively small sample size, which might preclude the detection of any significant improvements in OS and FFBF for patients treated with dose-escalated RT. Thirdly, the follow-up in our study was relatively short. Longer follow-up is needed to detect any differences in OS and FFBF in patients treated with doseescalation RT.
In conclusion, our results demonstrated favourable survival and biochemical outcomes for clinically localised prostate cancer treated with EBRT, in a cohort that consisted of $>60 \%$ with high-risk disease. Whilst dose escalation to beyond 74 Gy did not appear to increase biochemical control or improve OS, it came at a cost of increased rectal haemorrhage. Further prospective studies are needed to explore the value of dose escalation in risk-matched patient cohorts treated with and without ADT. Longer follow-up is required to refine survival and late toxicity outcomes. Harmonisation of radiation toxicity scoring and reporting within the research community is imperative to inform future developments in prostate cancer management.

\section{Conflicts of Interest}

The Authors declare no conflicts of interest with regard to this study.

\section{Authors' Contributions}

KM: Data collection, interpretation of data, manuscript writing; KL: Interpretation of data, revision of article; CCL: Interpretation of data, revision of article; DC: Interpretation of data, revision of article; KHO: Interpretation of data, revision of article; YYS: Interpretation of data, revision of article; JT: formulated the protocol, data collection, data analysis, interpretation of data, article writing.

\section{References}

1 Cancer incidence and mortality in singapore 2003-2012 (2015). Available at: https://www.nrdo.gov.sg/docs/librariesprovider3/ default-document-library/cancertrends_7312_web 128 e09a5c9d76bafab5aff000014cdee.pdf?sfvrsn=245962e4_0 (last accessed on 13/11/2019)

2 Cancer survival in singapore 1973-2012 (2015). Available at: https://www.nrdo.gov.sg/docs/librariesprovider3/defaultdocument-library/cancersurv_030915_final-w-appendices.pdf? sfvrsn=0 (last accessed on 13/11/2019)

3 Baade PD, Youlden DR, Cramb SM, Dunn J and Gardiner RA: Epidemiology of prostate cancer in the asia-pacific region. Prostate Int 1(2): 47-58, 2013. PMID: 24223402. DOI: 10.12954/PI.12014

4 Taitt HE: Global trends and prostate cancer: A review of incidence, detection, and mortality as influenced by race, ethnicity, and geographic location. Am J Mens Health 12(6): 1807-1823, 2018. PMID: 30203706. DOI: 10.1177/155798 8318798279

5 Hamdy FC, Donovan JL, Lane JA, Mason M, Metcalfe C, Holding P, Davis M, Peters TJ, Turner EL, Martin RM, Oxley J, Robinson M, Staffurth J, Walsh E, Bollina P, Catto J, Doble A, Doherty A, Gillatt D, Kockelbergh R, Kynaston H, Paul A, Powell P, Prescott S, Rosario DJ, Rowe E, Neal DE and Protec TSG: 10year outcomes after monitoring, surgery, or radiotherapy for localized prostate cancer. N Engl J Med 375(15): 1415-1424, 2016. PMID: 27626136. DOI: 10.1056/NEJMoa 1606220 
6 Roach M, 3rd, Ceron Lizarraga TL and Lazar AA: Radical prostatectomy versus radiation and androgen deprivation therapy for clinically localized prostate cancer: How good is the evidence? Int J Radiat Oncol Biol Phys 93(5): 1064-1070, 2015. PMID: 26581143. DOI: 10.1016/j.ijrobp.2015.08.005

7 Donovan JL, Hamdy FC, Lane JA, Mason M, Metcalfe C, Walsh E, Blazeby JM, Peters TJ, Holding P, Bonnington S, Lennon T, Bradshaw L, Cooper D, Herbert P, Howson J, Jones A, Lyons N, Salter E, Thompson P, Tidball S, Blaikie J, Gray C, Bollina P, Catto J, Doble A, Doherty A, Gillatt D, Kockelbergh R, Kynaston H, Paul A, Powell P, Prescott S, Rosario DJ, Rowe E, Davis M, Turner EL, Martin RM, Neal DE and Protec TSG: Patient-reported outcomes after monitoring, surgery, or radiotherapy for prostate cancer. N Engl J Med 375(15): 1425-1437, 2016. PMID: 27626365. DOI: 10.1056/NEJMoa1606221

8 Vora SA, Wong WW, Schild SE, Ezzell GA and Halyard MY: Analysis of biochemical control and prognostic factors in patients treated with either low-dose three-dimensional conformal radiation therapy or high-dose intensity-modulated radiotherapy for localized prostate cancer. Int J Radiat Oncol Biol Phys 68(4): 1053-1058, 2007. PMID: 17398023. DOI: 10.1016/j.ijrobp.2007.01.043

9 Zelefsky MJ, Yamada Y, Fuks Z, Zhang Z, Hunt M, Cahlon O, Park J and Shippy A: Long-term results of conformal radiotherapy for prostate cancer: Impact of dose escalation on biochemical tumor control and distant metastases-free survival outcomes. Int J Radiat Oncol Biol Phys 71(4): 1028-1033, 2008. PMID: 18280056. DOI: 10.1016/j.ijrobp.2007.11.066

10 Viani GA, Viana BS, Martin JE, Rossi BT, Zuliani G and Stefano EJ: Intensity-modulated radiotherapy reduces toxicity with similar biochemical control compared with 3-dimensional conformal radiotherapy for prostate cancer: A randomized clinical trial. Cancer 122(13): 2004-2011, 2016. PMID: 27028170. DOI: $10.1002 /$ cncr.29983

11 D'Amico AV, Whittington R, Malkowicz SB, Schultz D, Blank K, Broderick GA, Tomaszewski JE, Renshaw AA, Kaplan I, Beard CJ and Wein A: Biochemical outcome after radical prostatectomy, external beam radiation therapy, or interstitial radiation therapy for clinically localized prostate cancer. JAMA 280(11): 969-974, 1998. PMID: 9749478. DOI: 10.1001/ jama.280.11.969

12 Roach M, 3rd, Marquez C, Yuo HS, Narayan P, Coleman L, Nseyo UO, Navvab Z and Carroll PR: Predicting the risk of lymph node involvement using the pre-treatment prostate specific antigen and gleason score in men with clinically localized prostate cancer. Int J Radiat Oncol Biol Phys 28(1): 33-37, 1994. PMID: 7505775. DOI: 10.1016/0360-3016(94) 90138-4

13 Roach M, 3rd, Hanks G, Thames H, Jr., Schellhammer P, Shipley WU, Sokol GH and Sandler H: Defining biochemical failure following radiotherapy with or without hormonal therapy in men with clinically localized prostate cancer: Recommendations of the rtog-astro phoenix consensus conference. Int J Radiat Oncol Biol Phys 65(4): 965-974, 2006. PMID: 16798415. DOI: 10.1016/j.ijrobp.2006.04.029

14 Common terminology criteria for adverse events (ctcae) v4.03 (Jun 2010). Available at: https://www.eortc.be/services/doc/ctc/ ctcae_4.03_2010-06-14_quickreference_5x7.pdf (Last accessed on $13 / 11 / 2019$ )
15 Alicikus ZA, Yamada Y, Zhang Z, Pei X, Hunt M, Kollmeier M, Cox B and Zelefsky MJ: Ten-year outcomes of high-dose, intensity-modulated radiotherapy for localized prostate cancer. Cancer 117(7): 1429-1437, 2011. PMID: 21425143. DOI: 10.1002/cncr.25467

16 Aizawa R, Takayama K, Nakamura K, Inoue T, Kobayashi T, Akamatsu S, Yamasaki T, Ogawa O and Mizowaki T: Long-term outcomes of intensity-modulated radiation therapy combined with neoadjuvant hormonal therapy for japanese patients with non-metastatic prostate cancer. J Clin Oncol 36(6_suppl): 49-49, 2018. DOI: 10.1200/JCO.2018.36.6_suppl.49

17 Beckendorf V, Guerif S, Le Prise E, Cosset JM, Bougnoux A, Chauvet B, Salem N, Chapet O, Bourdain S, Bachaud JM, Maingon P, Hannoun-Levi JM, Malissard L, Simon JM, Pommier P, Hay M, Dubray B, Lagrange JL, Luporsi E and Bey P: 70 gy versus 80 gy in localized prostate cancer: 5-year results of getug 06 randomized trial. Int J Radiat Oncol Biol Phys 80(4): 1056-1063, 2011. PMID: 21147514. DOI: 10.1016/j.ijrobp. 2010.03.049

18 Zietman AL, Bae K, Slater JD, Shipley WU, Efstathiou JA, Coen JJ, Bush DA, Lunt M, Spiegel DY, Skowronski R, Jabola BR and Rossi CJ: Randomized trial comparing conventionaldose with high-dose conformal radiation therapy in early-stage adenocarcinoma of the prostate: Long-term results from proton radiation oncology group/american college of radiology 95-09. J Clin Oncol 28(7): 1106-1111, 2010. PMID: 20124169. DOI: 10.1200/JCO.2009.25.8475

19 Heemsbergen WD, Al-Mamgani A, Slot A, Dielwart MF and Lebesque JV: Long-term results of the dutch randomized prostate cancer trial: Impact of dose-escalation on local, biochemical, clinical failure, and survival. Radiother Oncol 110(1): 104-109, 2014. PMID: 24246414. DOI: 10.1016/j.radonc. 2013.09 .026

20 Dearnaley DP, Jovic G, Syndikus I, Khoo V, Cowan RA, Graham JD, Aird EG, Bottomley D, Huddart RA, Jose CC, Matthews JH, Millar JL, Murphy C, Russell JM, Scrase CD, Parmar MK and Sydes MR: Escalated-dose versus control-dose conformal radiotherapy for prostate cancer: Long-term results from the mrc rt01 randomised controlled trial. Lancet Oncol 15(4): 464-473, 2014. PMID: 24581940. DOI: 10.1016/S14702045(14)70040-3

21 Kuban DA, Tucker SL, Dong L, Starkschall G, Huang EH, Cheung MR, Lee AK and Pollack A: Long-term results of the m. D. Anderson randomized dose-escalation trial for prostate cancer. Int J Radiat Oncol Biol Phys 70(1): 67-74, 2008. PMID: 17765406. DOI: 10.1016/j.ijrobp.2007.06.054

22 Michalski JM, Moughan J, Purdy J, Bosch W, Bruner DW, Bahary JP, Lau H, Duclos M, Parliament M, Morton G, Hamstra D, Seider M, Lock MI, Patel M, Gay H, Vigneault E, Winter K and Sandler H: Effect of standard vs dose-escalated radiation therapy for patients with intermediate-risk prostate cancer: The nrg oncology rtog 0126 randomized clinical trial. JAMA Oncol 4(6): e180039, 2018. PMID: 29543933. DOI: 10.1001/jamaoncol.2018.0039

23 Pilepich MV, Winter K, Lawton CA, Krisch RE, Wolkov HB, Movsas B, Hug EB, Asbell SO and Grignon D: Androgen suppression adjuvant to definitive radiotherapy in prostate carcinoma--long-term results of phase iii rtog 85-31. Int J Radiat Oncol Biol Phys 61(5): 1285-1290, 2005. PMID: 15817329. DOI: $10.1016 / j . i j r o b p .2004 .08 .047$ 
24 Roach M, 3rd, Bae K, Speight J, Wolkov HB, Rubin P, Lee RJ, Lawton C, Valicenti R, Grignon D and Pilepich MV: Short-term neoadjuvant androgen deprivation therapy and external-beam radiotherapy for locally advanced prostate cancer: Long-term results of rtog 8610. J Clin Oncol 26(4): 585-591, 2008. PMID: 18172188. DOI: $10.1200 / \mathrm{JCO} .2007 .13 .9881$

25 Bolla M, Van Tienhoven G, Warde P, Dubois JB, Mirimanoff RO, Storme G, Bernier J, Kuten A, Sternberg C, Billiet I, Torecilla JL, Pfeffer R, Cutajar CL, Van der Kwast T and Collette L: External irradiation with or without long-term androgen suppression for prostate cancer with high metastatic risk: 10-year results of an eortc randomised study. Lancet Oncol 11(11): 1066-1073, 2010. PMID: 20933466. DOI: 10.1016/S1470-2045(10)70223-0

26 Jones CU, Hunt D, McGowan DG, Amin MB, Chetner MP, Bruner DW, Leibenhaut MH, Husain SM, Rotman M, Souhami L, Sandler HM and Shipley WU: Radiotherapy and short-term androgen deprivation for localized prostate cancer. N Engl J Med 365(2): 107-118, 2011. PMID: 21751904. DOI: 10.1056/ NEJMoa 1012348

27 Keating NL, O'Malley AJ and Smith MR: Diabetes and cardiovascular disease during androgen deprivation therapy for prostate cancer. J Clin Oncol 24(27): 4448-4456, 2006. PMID: 16983113. DOI: $10.1200 /$ jco.2006.06.2497

28 D'Amico AV, Denham JW, Crook J, Chen MH, Goldhaber SZ, Lamb DS, Joseph D, Tai KH, Malone S, Ludgate C, Steigler A and Kantoff PW: Influence of androgen suppression therapy for prostate cancer on the frequency and timing of fatal myocardial infarctions. J Clin Oncol 25(17): 2420-2425, 2007. PMID: 17557956. DOI: 10.1200/jco.2006.09.3369

29 Saigal CS, Gore JL, Krupski TL, Hanley J, Schonlau M and Litwin MS: Androgen deprivation therapy increases cardiovascular morbidity in men with prostate cancer. Cancer 110(7): 1493-1500, 2007. PMID: 17657815. DOI: 10.1002/ cncr.22933

30 Efstathiou JA, Bae K, Shipley WU, Hanks GE, Pilepich MV, Sandler HM and Smith MR: Cardiovascular mortality and duration of androgen deprivation for locally advanced prostate cancer: Analysis of rtog 92-02. Eur Urol 54(4): 816-823, 2008. PMID: 18243498. DOI: 10.1016/j.eururo.2008.01.021

31 Choe KS, Jani AB and Liauw SL: External beam radiotherapy for prostate cancer patients on anticoagulation therapy: How significant is the bleeding toxicity? Int J Radiat Oncol Biol Phys 76(3): 755-760, 2010. PMID: 19464123. DOI: 10.1016/ j.ijrobp.2009.02.026

32 Efstathiou JA, Bae K, Shipley WU, Hanks GE, Pilepich MV, Sandler HM and Smith MR: Cardiovascular mortality after androgen deprivation therapy for locally advanced prostate cancer: Rtog 85-31. J Clin Oncol 27(1): 92-99, 2009. PMID: 19047297. DOI: $10.1200 /$ jco.2007.12.3752

33 Alibhai SM, Duong-Hua M, Sutradhar R, Fleshner NE, Warde P, Cheung AM and Paszat LF: Impact of androgen deprivation therapy on cardiovascular disease and diabetes. J Clin Oncol 27(21): 34523458, 2009. PMID: 19506162. DOI: 10.1200/jco.2008.20.0923
34 Do NL, Nagle D and Poylin VY: Radiation proctitis: Current strategies in management. Gastroenterol Res Pract 2011: 917941, 2011. PMID: 22144997. DOI: 10.1155/2011/917941

35 Fonteyne V, Villeirs G, Lumen N and De Meerleer G: Urinary toxicity after high dose intensity modulated radiotherapy as primary therapy for prostate cancer. Radiother Oncol 92(1): 4247, 2009. PMID: 19356817. DOI: 10.1016/j.radonc.2009.03.013

36 Shadad AK, Sullivan FJ, Martin JD and Egan LJ: Gastrointestinal radiation injury: Symptoms, risk factors and mechanisms. World J Gastroenterol 19(2): 185-198, 2013. PMID: 23345941. DOI: 10.3748/wjg.v19.i2.185

37 Delobel JB, Gnep K, Ospina JD, Beckendorf V, Chira C, Zhu J, Bossi A, Messai T, Acosta O, Castelli J and de Crevoisier R: Nomogram to predict rectal toxicity following prostate cancer radiotherapy. PLoS One 12(6): e0179845, 2017. PMID: 28640871. DOI: 10.1371/journal.pone.0179845

38 Zhen Y, Jiang Y, Yuan L, Kirkpartrick J, Wu J and Ge Y: Analyzing the usage of standards in radiation therapy clinical studies. IEEE EMBS Int Conf Biomed Health Inform 2017: 349352, 2017. PMID: 29707698. DOI: 10.1109/BHI.2017.7897277

39 Trotti A, Colevas AD, Setser A, Rusch V, Jaques D, Budach V, Langer C, Murphy B, Cumberlin R, Coleman CN and Rubin P: Ctcae v3.0: Development of a comprehensive grading system for the adverse effects of cancer treatment. Semin Radiat Oncol 13(3): 176-181, 2003. PMID: 12903007. DOI: 10.1016/S10534296(03)00031-6

40 Cox JD, Stetz J and Pajak TF: Toxicity criteria of the radiation therapy oncology group (rtog) and the european organization for research and treatment of cancer (eortc). Int J Radiat Oncol Biol Phys 31(5): 1341-1346, 1995. PMID: 7713792. DOI: 10.1016/ 0360-3016(95)00060-C

41 Jacobs CD, Chun SG, Yan J, Xie XJ, Pistenmaa DA, Hannan R, Lotan Y, Roehrborn CG, Choe KS and Kim DW: Aspirin improves outcome in high risk prostate cancer patients treated with radiation therapy. Cancer Biol Ther 15(6): 699-706, 2014. PMID: 24658086. DOI: $10.4161 /$ cbt.28554

42 Zaorsky NG, Buyyounouski MK, Li T and Horwitz EM: Aspirin and statin nonuse associated with early biochemical failure after prostate radiation therapy. Int J Radiat Oncol Biol Phys 84(1): e1317, 2012. PMID: 22652109. DOI: 10.1016/j.ijrobp.2012.02.050

43 Prostate pelvic lymph nodes. Available at: https://www.rtog.org/ CoreLab/ContouringAtlases/ProstatePelvicLymphNodes.aspx (last accessed on 14/11/2019)
Received October 31, 2019

Revised November 12, 2019

Accepted November 15, 2019 